\title{
$\mathrm{PH}$
}

\section{Proyecto Outings. El gran museo urbano y libre}

\begin{abstract}
En 2014, en París y Londres, Julien Casabianca, un artista visual y cineasta francés, inicia Outings Project, que a día de hoy se extiende por los cinco continentes, por 200 ciudades repartidas entre más de 80 países. Su objetivo se está cumpliendo: sacar el arte a las calles; trasladar su belleza desde las paredes de los museos a las de las ciudades. Este proyecto participativo global es una invitación a cualquiera que haya fotografiado con su cámara o teléfono móvil una obra de arte en algún museo o galería, para que la libere en la calle. ¿Cómo? Imprimiéndola en gran formato, recortando al personaje y pegándola en el lugar adecuado, en alguna pared, para que cualquiera pueda verla. En España podemos ver obras liberadas en Málaga, Barcelona, Madrid... Cualquiera puede participar.
\end{abstract}

Julien Casabianca | Le Laboratoire de la Création (Traducción: Victoria Frensel)

URL de la contribución <www.iaph.es/revistaph/index.php/revistaph/article/view/3685>

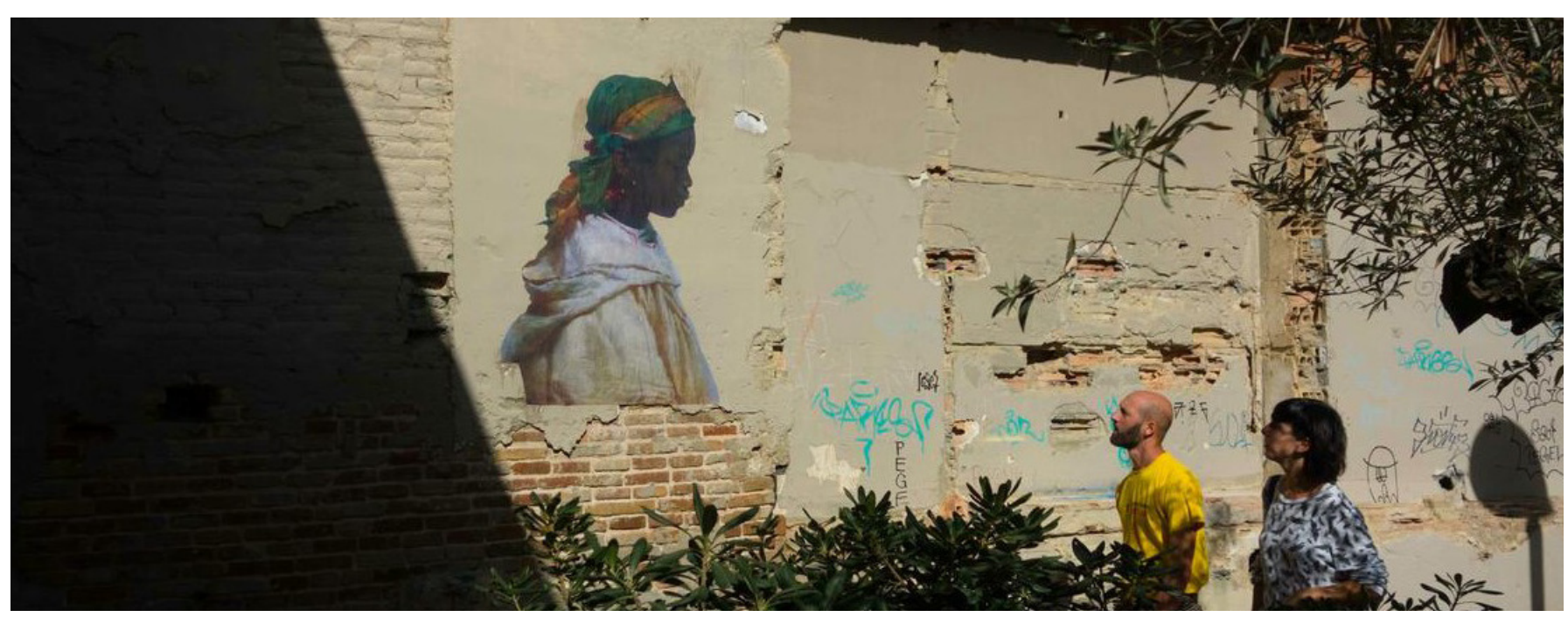

Obra liberada en Barcelona, donde colaboran en el proyecto el museo Picasso y el Museo Nacional d'Art de Catalunya | foto Outings Project

Nos habíamos convertido en vegetarianos de museos. Peor todavía: en veganos de museos, en crudívoros fundamentalistas. Esa era la doctrina: cómete el arte crudo, sin cocinarlo, sin sal, sin especias. Para ver arte en un museo lo único permitido eras tú, la única actitud correcta era la de "tú contigo a solas", sin nada más, sólo tu ropa, ni siquiera tu bolso. De alguna manera la desnudez como una liberación, como una forma de abrirse a la obra de arte. Pero algo pasó. El trabajo de los ordenadores que no dejaron de calcular durante los once años del programa espacial Apolo se traduce ahora en una única búsqueda en Google. Y aun así, ¿os gustaría que las per- sonas siguiesen siendo crudívoras del arte en un museo cuando en sus bolsillos llevan más poder que el que nos mandó 17 veces a la Luna? Nos sorprende el hecho de que no se queden "desnudas" y "puras" delante del cuadro, únicamente conectadas con sus ojos, mirando, sintiendo. Por el contrario las vemos sacando fotos con sus móviles, y pensamos que se están perdiendo algo. Pero hoy día no solamente queremos mirar, también queremos mostrar, queremos compartir nuestros sentimientos. Son los tiempos de las redes sociales. Del mismo modo que antes lo fue de la pintura. La obra de arte era la mejor tecnología para compartir. Su verdadero valor 

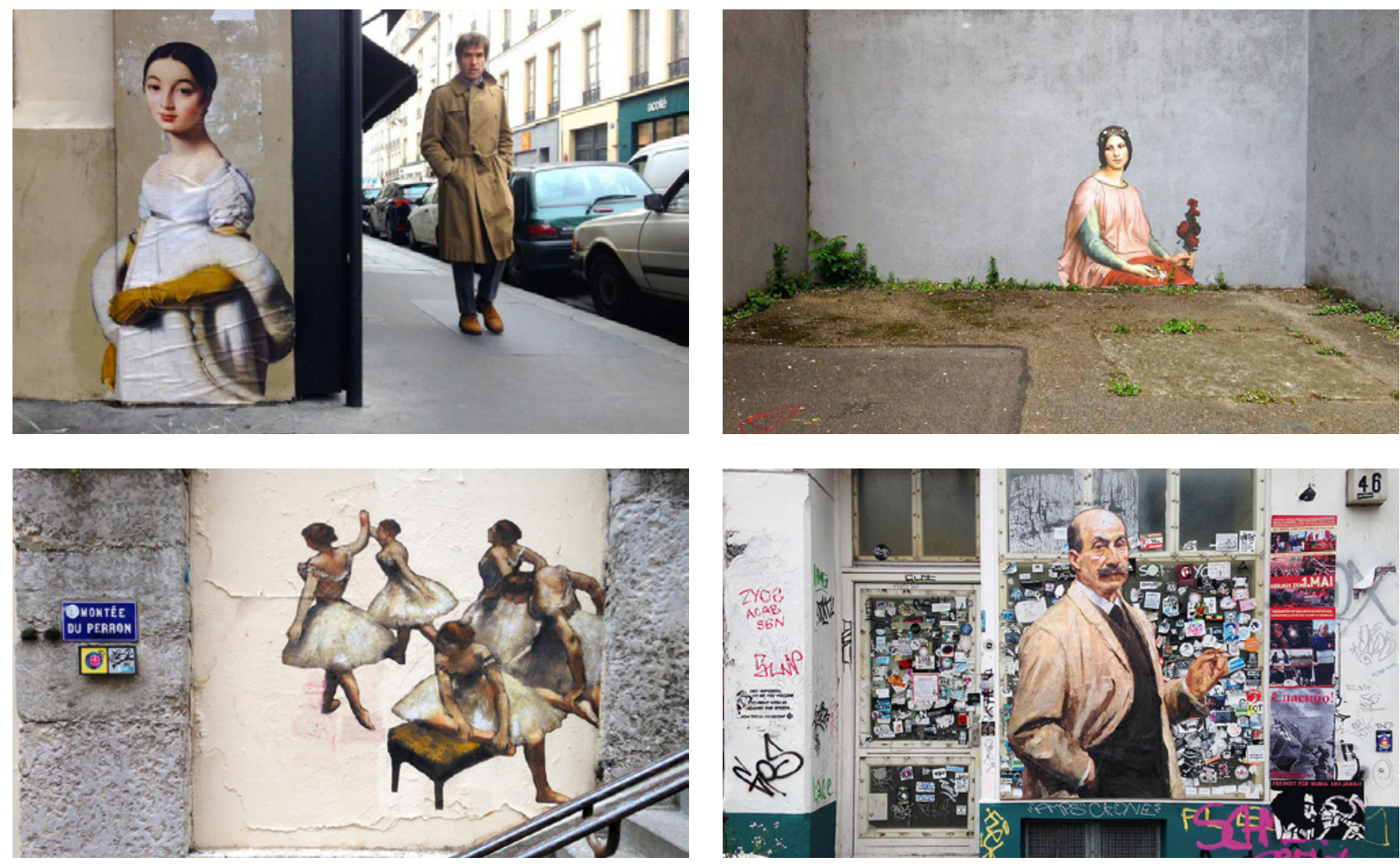

Retratos en las calles de Francia (París y Lyon) y Alemania (Hamburgo) | fotos Outings Project

era su función social, como indicador de un modelo de vivir y de recordar. Resumiendo: esto es justo lo que hacemos ahora con nuestros móviles e Instagram. Con la mejor tecnología de nuestro tiempo.

Sí, vamos a sacar fotos en los museos. Y se supone que así no estamos mirando de la manera correcta porque nuestra atención se diluye. Al contrario, cuando vas a sacar una foto te estás concentrando en un tema, no te estás distrayendo. Sí, vamos a sacar fotos, no vamos a mirar estando "desnudos". Además, lo que estamos mirando no es el patrimonio del museo, es nuestro patrimonio. El museo solo es el encargado de conservar y mostrar, pero los propietarios somos nosotros. Y miramos como nos da la gana. Por primera vez en la corta historia de los museos la gente está delante de un cuadro con más tecnología en la mano de la que disponía el pintor mismo. Algo ha cambiado profundamente. Son los tiempos de la reapropiación.
Outings es eso: reapropiación. Yo hago una foto de un retrato en un museo de arte y lo pego en la calle, y descubro cómo la gente se conmueve más y está más agradecida en barrios pobres. Es allí donde voy a pegarlo, porque es de donde soy yo también. Cuando me dedico a pegar durante el día -no a escondidas- la gente comparte conmigo sus sensaciones, y es precioso. Cuando les digo que lo que estoy pegando viene de un museo, me dicen que fueron al colegio muy poco tiempo... Es alucinante cómo la gente asocia el museo al conocimiento. Y se sienten excluídos. Yo soy de un barrio pobre y por eso sé lo mucho que necesitamos la belleza, lo mucho que necesitamos reapropiarnos del arte de los museos, porque muchas veces sentimos que el arte es para los ricos y para los turistas, no para los vecinos, aunque esto no sea cierto. Hablo de lo que creo que mucha gente siente. ¿Por qué no van al museo municipal aunque vivan cerca? Creo que no lo hacen porque intuyen que el museo es un lugar de conocimiento, y ellos sienten modestia acerca 
de su propio conocimiento, creen que no saben mucho, y sienten que el museo no es para ellos.

Y esto es así porque en un museo es difícil encontrar emociones, se trata más bien un lugar de conocimiento, donde el arte se clasifica por siglos, periodos, pero no por emociones: no hay una sala del amor, o del miedo, o del odio o de la amistad. Los museos son algo increíble, pero para mucha gente es difícil sentir algo allí dentro. Bien, pues yo soy artista. Y estoy aquí para enseñarle algo al mundo. No estoy para arreglarlo. Pero sí puedo mostrarlo. $Y$ esto es lo que hace Outings.

Por este motivo elijo en un museo algunos cuadros sin conexión, aislados, sin razón previa. Decido que sean aquellos que me proporcionan emociones. Yo necesito belleza, emociones, sentimientos. Es simplemente una nueva manera de mirar en un museo: entras con la idea de llevarte contigo a la calle algunos retratos. No eres pasivo, sino totalmente activo, miras los cuadros con una visión propia y sacas una foto, para luego pegarla en la calle. Es fácil de hacer. Por eso casi 200 personas lo están haciendo ahora mismo, se unen a Outings en todos los países de los cinco continentes.

Es una manera de descubrir cómo se puede compartir el mismo entorno urbano con distintas generaciones y distintos tipos de personas: cuando pegamos nos llegan las mismas reacciones tanto de jóvenes como de mayores, tanto del adolescente rapero como el abuelete. Es belleza para todo el mundo, incluso si el viejo odia el arte callejero. Quizás ocurre esto porque la estética de los cuadros pertenece a nuestra cultura común, y está por encima de una cuestión generacional. Yo creo que un cuadro de la época antigua o del siglo XVIII contiene una parte de la historia de la estética, una parte de la construcción de un estilo clásico, y también del diseño moderno o del arte gráfico contemporáneo. En un grafiti hay inevitablemente un rastro del impacto del Renacimiento o del Impresionismo -el grafiti y el arte callejero no vienen de la nada.

Como se trata de retratos, antes de ver un cuadro, lo que estás viendo es una persona. Ojos. Rostro. Existencia. Evidentemente del pasado, pero una per- sona que pasa por delante entre otras personas que pasan por delante. Un anónimo entre anónimos. No necesitas saber más.

El proyecto Outings empezó porque vi una vez una chica muy guapa en una pared, prisionera en un cuadro, en un marco, prisionera del castillo -del Museo del Louvrey tuve una pulsión del tipo "príncipe azul" para liberarla. Empezó como una broma. Pero cuando pegué el retrato de la chica en la calle fue una revelación. Hay un poder inesperado en este acto. No es legal, de acuerdo. Pero en Los Angeles la policía llegó justo cuando íbamos a pegar en la pared un ángel desnudo de 3 metros. Cuando dijimos que aquello provenía de un museo colocamos los policías en una difícil situación. Para ellos, en su representación del mundo, era difícil clasificar algo que procedía de un museo como vandalismo, considerar el arte clásico como algo degradado... Simplemente les dijimos que necesitábamos algunos minutos para terminar, hacer una foto y después quitarlo. Ellos accedieron. Mientras tanto los vecinos nos defendieron, y pidieron a los policías que dejaran el collage en el muro -ifueron nuestros abogados!-Así que, ante la presión de la gente, los policías aceptaron, se hicieron una fotos con los vecinos y con nosotros y lo compartieron en Instagram. Fue un gran momento. Honestamente, no sufrimos ninguna consecuencia. Puede que alguien quitara el retrato que acabábamos de pegar, pero la acción fue tan bonita... ¿qué más se podía pedir?

Mis retratos están dentro de la interacción social, no son espectadores, no hacen publicidad (no quieren nada de ti), son alguien anónimo más, como tú que pasas por delante, de alguna manera algo perdido en ese muro, como tú lo estás en la calle, en la propia vida.

Ahora hay museos en el mundo entero que me invitan a visitar sus colecciones, y a pegar en la calle, con el permiso de la ciudad. A veces lo hago a solas, a veces con gente joven de zonas pobres, y para cerrar el ciclo expongo en museos las fotos de mis Outings-collages en las calles. Así lo hice en el Museo de Arte e Historia de Ginebra, en el Museo de Artes y Jardines Cummer en Jacksonville, Estados Unidos, en el Museo de Ixelles en Bélgica o en el Museo Arocena en Torreón, México. 